4 Niall Dickson, Chief Executive of the NHS Confederation, which represents organisations across the healthcare sector, said: 'Preventing illness and disease is huge area with enormous potential - much of it extending well beyond the NHS.

'We need to support interventions that have been shown to work - from drugs that prevent strokes and heart disease, to tackling obesity among children.

'Of course, we have been here before and the recent record of cutting public health spending must now be reversed.'

1. Department of Health and Social Care. Prevention is better than cure: Our vision to help you live well for longer (5 November 2018). Available at https:// www.gov.uk/government/publications/prevention-is better-than-cure-our-vision-to-help-you-live-well-forlonger. (accessed on 5 November 2018).

\title{
Budget will mean less spending on workforce training
}

Less money will be spent training the NHS workforce including dentists, doctors and nurses, it has been claimed, following the recent Budget delivered on 29 October 2018 by Chancellor Philip Hammond.

In his Budget, Hammond confirmed the announcement made earlier this year that the NHS would receive a $£ 20.5$ billion increase in funding over the next five years.

Following the speech, think tank the Health Foundation produced an analysis that said the NHS England resource budget would increase by $£ 5.1$ billion in real terms next year (including $£ 1.25$ billion to cover additional pension costs.

The Department of Health and Social Care (DHSC) resource budget (which includes NHS England as well as wider health spending) was only increasing by $£ 4$ billion, therefore wider health spending would see a $£ 1$ billion reduction next year, unless the $£ 1.25$ billion was added to the published DHSC resource budget.

The impact of this would mean cuts to spending across public health, workforce training and capital investment in buildings and equipment, said the Health Foundation.

Professor Anita Charlesworth, Director of Research and Economics for the Health Foundation, said: 'The NHS was the clear winner in the Chancellor's budget but there is a risk that it won't feel like that in hospitals and GP surgeries over the coming year. Extra funding starts next year and rises to $£ 20.5$ billion in 2023-24. The money is not for front-line NHS services.

'It excludes wider areas of vital health spending where funding is also desperately needed; public health, workforce training and capital investment.'

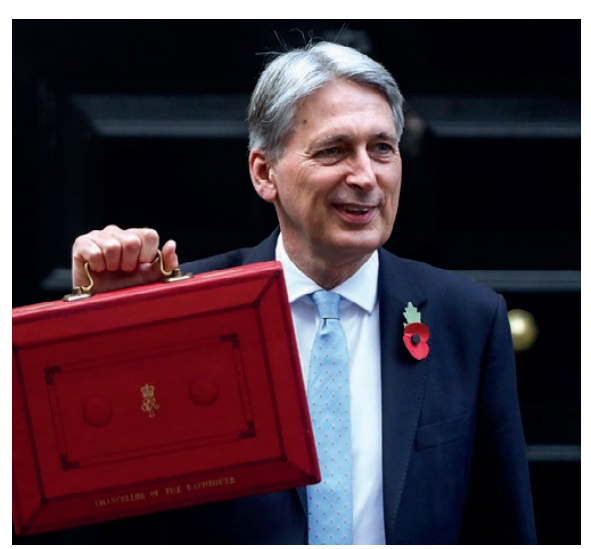

Chancellor of the Exchequer, Philip Hammond

Other announcements made in the Budget included:

- From the next financial year, the amount you can earn before paying tax will rise from $£ 11,850$ to $£ 12,500$, and the threshold for the higher rate of tax will increase from $£ 46,350$ to $£ 50,000$

- The government reformed the off-payroll working rules for the public sector in April 2017. The latest budget announced an extension of these reforms to the private sector too, to ensure individuals who effectively work as employees are taxed as employees, even if they are technically self-employed. Small companies and organisations will be exempt, and the Treasury will provide detailed guidance to medium and large organisations ahead of implementation in April 2020

- From April 2019, the National Living Wage will increase from $£ 7.83$ to $£ 8.21$

- Business rates will be cut by a third for retail properties with a rateable value below $£ 51,000$ for 2 years from April 2019

- Business rates will be revaluated from 2021. 